\title{
Matriz óssea homóloga desmineralizada na preparação de falhas ósseas segmentares produzidas no rádio de coelhos
}

\author{
Repair of segmental defects produced in the radii rabbit by \\ homologous demineralized bone matrix
}

\author{
Alessandra Maria da Silva ${ }^{1}$ Ricardo Junqueira Del Carlo ${ }^{2}$ \\ Marlene Isabel Vargas Viloria ${ }^{3}$ Alessandra Sayegh Silva ${ }^{4}$ \\ Richard Rocha Filgueiras ${ }^{4}$
}

RESUMO

No presente trabalho, foram avaliados os potenciais osteoindutor e osteocondutor da matriz óssea homóloga desmineralizada (MOD) em ácido clorídrico 0,6 $\mathrm{N}$ e conservada em etanol $70 \%$ e sua utilização no preenchimento de falhas osteoperiosteais induzidas em rádio de coelhos. $O$ rádio operado de todos os animais foi radiografado imediatamente após a cirurgia e na $3{ }^{a}, 6^{a}, 9^{a}$ e $12^{a}$ semanas após. No grupo tratado, sete animais foram sacrificados a cada três semanas, sendo realizadas tomografia computadorizada e avaliações macro e microscópica e da fluorescência óssea à tetraciclina. Os animais do grupo controle foram sacrificados na $12^{\text {a }}$ semana de pós-operatório. Foi constatado que a matriz acelerou o processo de formação óssea, devido a fatores indutores inerentes que atuaram sobre as células dos tecidos adjacentes e que os canais vasculares, as lacunas e o canal medular vazios da MOD, serviram de arcabouço para a penetração celular, determinando osteocondução.

Palavras-chave: falhas ósseas, enxerto ósseo, reparação óssea.

\section{ABSTRACT}

In order to evaluate osteoinduction and osteoconduction of the homologous demineralized bone matrix (DBM), processed in $\mathrm{HCl} 0.6 \mathrm{~N}$ solution for 24 hours and preserved in $70 \%$ ethanol solution, radial fragments were implanted in radius of adults rabbits. The animals were sacrificed at 3, 6, 9 and 12 post-operative weeks and the control group was sacrificed in 12 post-operative weeks. Radiographic exams of the operated radii were performed immediately after surgery and 3, 6, 9 and 12 post-operative weeks. After euthanasia, computed tomography, macroscopic, microscopic and tetracycline fluorescence exams were performed. DBM preserved its osteoinductive property and remains sterile. The empty spaces are favorable to osteoconduction and its growth factors induce osseous formation.

Key words: bone defects, bone graft, bone repair.

\section{INTRODUÇÃO}

O termo osteocondução aplica-se ao processo tridimensional observado quando estruturas porosas são implantadas no osso ou adjacências. $\mathrm{O}$ processo é caracterizado por um crescimento inicial de tecido fibrovascular que invade a estrutura e é seguido por deposição de osso novo diretamente sobre ela. $\mathrm{O}$ substrato osteocondutor não é viável, mas age como um arcabouço passivo cuja presença direciona o crescimento interno de osso e de tecido fibrovascular (CORNELL \& LANE, 1998).

Para TULI \& SINGH (1978), a matriz óssea desmineralizada (MOD) não apresenta atividade osteogênica, e sim osteoindutora. Após enxertia de MOD em abdômen de coelho, estes autores observaram que, nos estágios iniciais de incorporação, a área de novo osso correspondeu ao tamanho e à forma da matriz enxertada, sugerindo que a indução óssea foi localizada na substância e sobre a sua superfície. A maior parte do osso inicialmente formou-se a partir da diferenciação

${ }^{1}$ Médico Veterinário, Mestre, União Educacional do Planalto Central, UNIPLAC, DF.

${ }^{2}$ Médico Veterinário, Doutor, Professor Titular, Departamento de Veterinária (DVT), Universidade Federal de Viçosa (UFV),

36570-000, Viçosa, MG. E-mail:ricarlo@ufv.br. Autor para correspondência.

${ }^{3}$ Médico Veterinário, Doutor, Professor Adjunto, DVT, UFV.

${ }^{4}$ Médico Veterinário, Mestrando, DVT, UFV. 
de células tronco em células osteoprogenitoras, embora algumas áreas de formação de cartilagem e osso endocondral tenham sido observadas.

Uma vantagem da utilização da MOD é que grandes quantidades de material osteoindutor pode ser previamente preparado (VAIL et al., 1994). Apesar da aparente presença da proteína óssea morfogenética (BMP) no enxerto homólogo ósseo desmineralizado, comparações clínicas do sucesso do tratamento usando enxertos homólogos mineralizados e desmineralizados produzem resultados similares, embora o padrão do primeiro seja osteocondutor, enquanto o segundo é considerado osteoindutor (SCHWARTZ et al., 1998).

A incorporação de osso desvitalizado no hospedeiro depende de neovascularização e da disponibilidade de células mesenquimais indiferenciadas. Nesse aspecto, a musculatura apresenta capacidade de fornecer células tronco mesenquimais, que permitem o início da formação óssea em resposta aos fatores osteogênicos existentes no enxerto homólogo transplantado (BROWN et al., 1997).

Em transplantes ósseos, o material orgânico e mineral do enxerto deve ser reabsorvido antes que a completa substituição por osso novo possa ser efetuada. O conteúdo mineral residual deve sofrer reabsorção antes que a matriz colagenosa e a BMP possam estimular a osteoindução (HOSNY \& SHARAWY, 1985). Presumivelmente, quanto mais minerais são removidos, mais BMPs tornam-se expostas e solubilizadas da MOD (ZHANG et al., 1997).

A MOD é menos imunogênica do que o osso homólogo mineralizado (MORONE \& BODEN, 1998). Portanto, a remoção adequada do mineral além de tornar mais disponíveis as proteínas osteoindutoras, também abole ou reduz a expressão de antígeno da matriz óssea (HOSNY \& SHARAWY, 1985).

NADE \& BURWELL (1977) demonstraram que diferentes ácidos usados para desmineralizar o osso, antes da implantação, afetaram suas propriedades químicas e bioquímicas. Os implantes mineralizados ocasionaram a produção de células gigantes multinucleadas do tipo corpo estranho, já nos desmineralizados em $\mathrm{HCl}$ não houve formação destas células. Após a desmineralização, TULI \& SINGH (1978) sugeriram que o etanol a $70 \%$ pode ser um bom agente preservador, pois evita a desnaturação das proteínas osteoindutoras.

Substâncias fluorescentes com afinidade pelo tecido ósseo, como alizarina, isótopos radioativos, chumbo e tetraciclina, são depositadas em altas concentrações em menos de $1 \%$ do esqueleto, que corresponde a áreas de metabolismo ósseo elevado e em concentrações relativamente baixas na massa óssea restante (URIST \& McLEAN, 1963).

Considerando que, apesar de o enxerto ósseo mais efetivo na prática clínica ser o osso autógeno fresco, persiste a necessidade do uso de um material osteoindutor e osteocondutor que possa ser coletado e estocado, eliminando problemas inerentes ao enxerto autógeno, como quantidade restrita e necessidade de procedimento cirúrgico concomitante, o presente trabalho objetivou avaliar o uso da MOD na reparação de falhas segmentares produzidas no rádio de coelhos.

\section{MATERIAL E MÉTODOS}

O experimento foi conduzido no Departamento de Veterinária da Universidade Federal de Viçosa, em 31 coelhos adultos da raça Nova Zelândia Branco. O protocolo anestésico consistiu de préanestesia com acepromazina ${ }^{\mathrm{a}}(0,2 \mathrm{mg} / \mathrm{kg}$, IV) e anestesia dissociativa geral com tiletamina/zolazepam ${ }^{\mathrm{b}}(15 \mathrm{mg} /$ $\mathrm{kg}$, IV). Cada coelho recebeu $40.000 \mathrm{UI} / \mathrm{kg}$, IM, de penicilina $\mathrm{G}$ benzatina $^{\mathrm{c}}$, logo após a medicação préanestésica. Após os procedimentos cirúrgicos, os animais foram alojados individualmente em gaiolas, recebendo ração comercial e água ad libitum.

A MOD foi preparada a partir de rádios de coelhos sacrificados com sobredose anestésica. O tecido mole adjacente ao osso foi removido com bisturi e de forma asseptica. Os ossos foram desmineralizados, por imersão em $\mathrm{HCl} 0,6 \mathrm{~N}$, em temperatura ambiente e foram considerados totalmente desmineralizados quando se apresentavam moles, transparentes e flexíveis. A MOD foi estocada em etanol $70 \%$, em temperatura ambiente, por, no mínimo 15 dias, até o momento do uso.

Para os procedimentos cirúrgicos, cada animal foi posicionado em decúbito lateral esquerdo, e o membro anterior direito foi operado. Durante a cirurgia foi realizada uma falha óssea pela remoção de um segmento osteoperiosteal do rádio, em todo o seu diâmetro e com $1 \mathrm{~cm}$ de comprimento, localizado a $3 \mathrm{~cm}$ da articulação rádiocárpica, por intermédio de serra elétrica circular ${ }^{\mathrm{d}}$. A MOD preservada, preparada nas mesmas dimensões da falha, foi lavada em solução fisiológica, e enxertada na falha. Os tecidos muscular e subcutâneo foram aproximados com fio absorvível 3-0 e a síntese da pele foi feita com fio inabsorvível. Os animais do grupo controle foram submetidos ao mesmo procedimento cirúrgico, porém não receberam a implantação da MOD.

Sete animais foram sacrificados na terceira, sexta, nona e décima segunda semanas de pós- 
operatório, constituindo o grupo I (GI). O grupo controle (GII), constituído de três animais, foi sacrificado ao final de 12 semanas.

Foram realizadas radiografias nos membros operados, utilizando a incidência médio lateral, imediatamente após a cirurgia e a cada três semanas até o dia do sacrifício. O preenchimento da falha óssea foi classificado em ausente, parcial e total. Para o estudo do preenchimento das falhas, foi utilizada análise descritiva.

À época do sacrifício, três coelhos de cada intervalo de tempo e os animais do GII tiveram seus membros operados submetidos à avaliação por tomografia computadorizada, objetivando apreciação do processo de reparação da falha. À necropsia, os rádios de todos os animais operados foram dissecados e foi observada a característica do tecido que preenchia a falha, o volume do calo e a presença de lacuna (total, parcial e ausente).

O exame histológico foi realizada no rádio operado de dois animais de cada intervalo de tempo. Dos rádios coletados, foram obtidos três fragmentos ósseos: dois envolvendo a extremidade da falha óssea, juntamente com o tecido remanescente proximal e distal, e um envolvendo a área intermediária. Os fragmentos foram fixados em formol $10 \%$ tamponado e posteriormente descalcificados e submetidos à rotina histológica. Foram realizados cortes longitudinais nos fragmentos proximal e distal, para permitir a avaliação da integração receptor/enxerto, e cortes transversais no fragmento médio, que foram corados por hematoxilina e eosina, examinados ao microscópio óptico. Foram avaliadas a presença de tecido osteóide, a integração enxerto/receptor, o tipo de ossificação, a maturidade do osso novo formado e a presença de reação inflamatória. No GII, foi realizada avaliação da falha, na décima segunda semana.

A deposição de osso novo no espaço de tempo determinado foi evidenciada pela fluorescência da tetraciclina. Para este exame, dois coelhos de cada intervalo de tempo, receberam $30 \mathrm{mg} / \mathrm{kg}$ de tetraciclina ${ }^{\mathrm{e}}$, IM, por três dias consecutivos. O mesmo protocolo foi repetido após intervalo de uma semana. Os coelhos foram sacrificados 48 horas após a última aplicação e o material foi processado segundo técnica preconizada por VOLPON (1985). O material foi examinado em fotomicroscópio de fluorescência por epiiluminação, com filtro triplo $\mathrm{DFE}^{\mathrm{f}}$ e fotografado.

\section{RESULTADOS E DISCUSSÃO}

A coleta e o preparo do osso para obtenção da MOD foram procedimentos simples, mas dependentes de trabalho acurado e de prevenção de contaminação. A desmineralização em $\mathrm{HCl} 0,6 \mathrm{~N}$ aconteceu, em média, em 24 horas após a imersão, quando a matriz apresentou-se mole, transparente e flexível, e o etanol $70 \%$ em temperatura ambiente mostrou-se um bom método de preservação, pois não foi observada qualquer contaminação da área de implante durante o experimento.

Os resultados da pesquisa confirmam que os métodos de desmineralização e de preservação não ocasionaram a desnaturação da proteína osteoindutora, cujo potencial situa-se em moléculas da matriz e não nas células ósseas, acelerando processo de formação óssea, como observado nos trabalhos de NADE \& BURWELL (1977), TULI \& SINGH(1978) e BROWN et al. (1997). Além disso, mantiveram a propriedade de osteocondução, criando um ambiente estrutural favorável.

Na radiografia, realizada imediatamente após a cirurgia, não se evidenciou material radiopaco. Já a análise das radiografias periódicas demonstrou que, na terceira semana após a cirurgia, havia preenchimento total da falha óssea em $60 \%$ dos animais e parcial em $35 \%$ dos coelhos que receberam enxerto de MOD, enquanto que, nos animais do GII, as falhas permaneciam sem preenchimento. Na sexta semana foi observada evolução do processo de reparação, com preenchimento de todas as falhas, sendo em $81 \%$ dos casos total e em $19 \%$ parcialmente, enquanto no grupo controle $33 \%$ dos animais apresentavam preenchimento parcial (Figura 1).

No GI, foi observado, na nona semana, por meio da análise radiográfica e tomografia computadorizada, que as falhas enxertadas estavam totalmente preenchidas. No grupo controle, na nona e décima segunda semanas, o processo de reparação demonstrava evolução, mas em todos os casos, as falhas permaneciam parcialmente preenchidas (Figura 1).

Em todas as radiografias, a primeira evidência foi uma radiopacidade na área do implante, caracterizada por densidade irregular (Figura 1, A3) e a atividade máxima se iniciava no periósteo ulnar e nas extremidades distal e proximal do implante. Posteriormente, o implante foi se tornando mais radiopaco e coberto por uma ponte óssea que foi contínua com o osso receptor proximal e distalmente (Figura 1, A9). Em 60\% dos enxertos, no osso recémformado evidenciavam-se áreas radiopacas além da superfície do osso receptor (Figura 1, A9). Com a maturidade, a remodelação demonstrava tendência à recuperação do formato de eixo, caracterizando um processo de reabsorção do calo ósseo, característica observada principalmente na décima segunda semana (Figura 1, A12). 

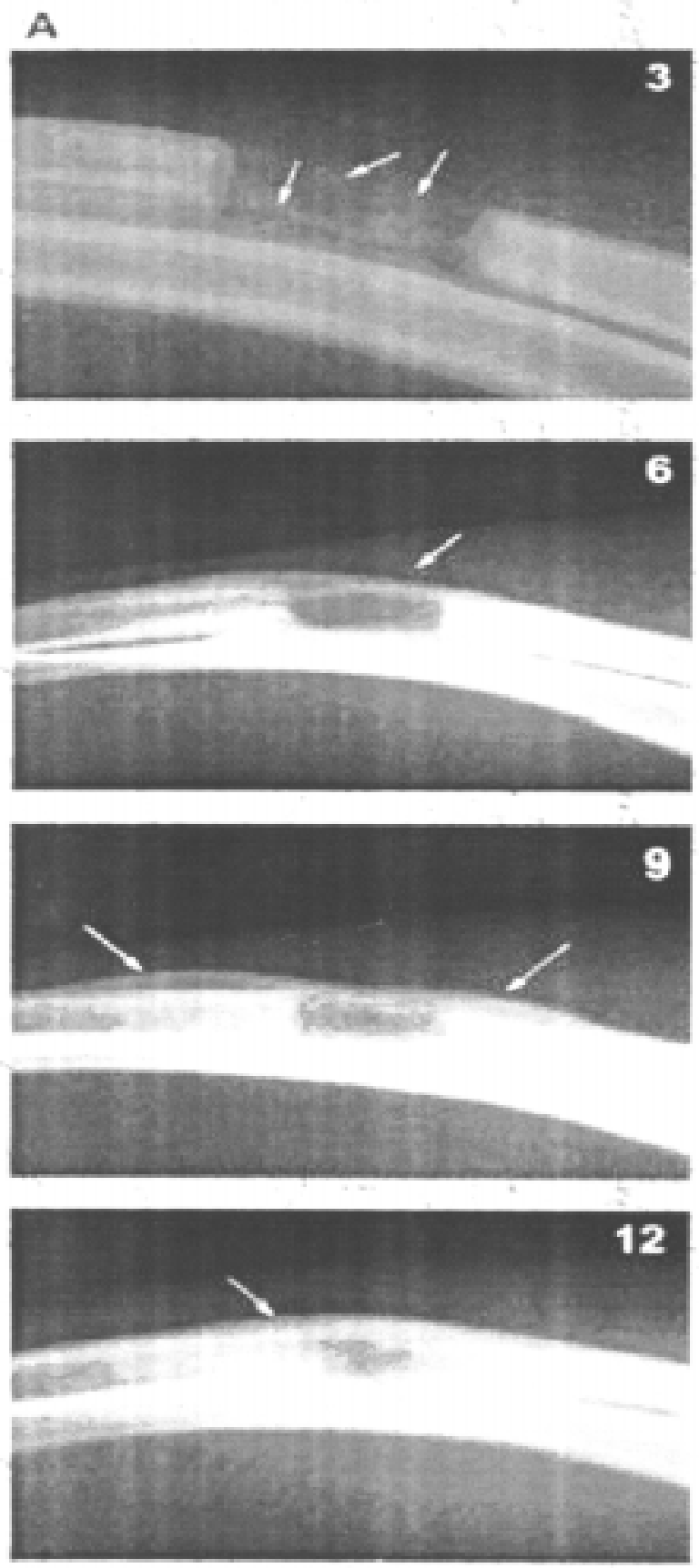

B
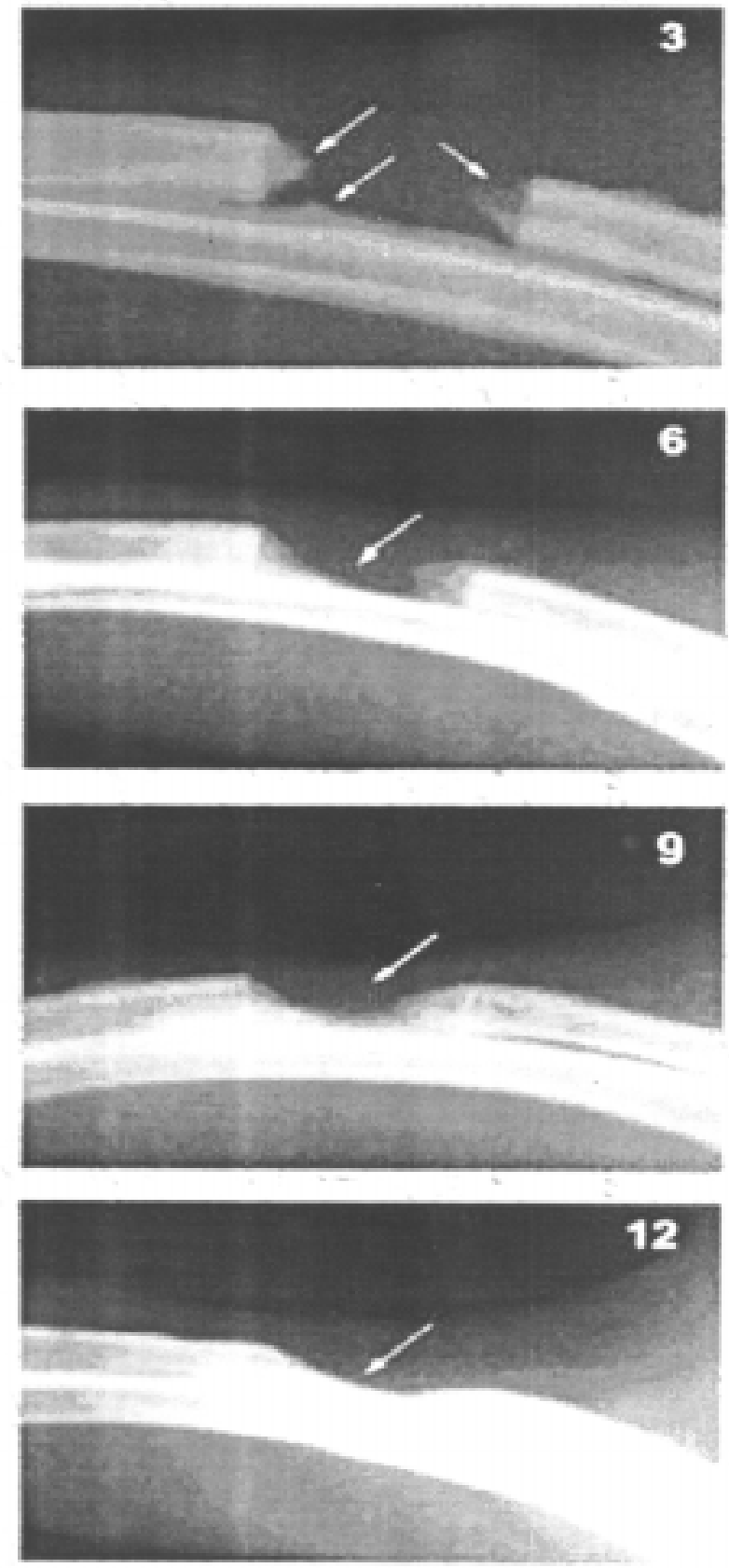

Figura 1 - A: evolução do processo de reparação da falha óssea criada no rádio de um coelho do GI. O número representa o tempo em semanas após implantação da MOD. 3: áreas de radiopacidade irregular no interior do implante (setas). 6: preenchimento total da falha por material radiopaco. 9: ponte óssea ligando as extremidades. 12: tendência a remodelação, evidenciando cortical (seta) e canal medular (seta no círculo). B: reparação da falha criada no rádio de um animal do GII. 3: início de formação óssea partindo das extremidades da falha e do periósteo ulnar (setas). 6, 9 e 12: preenchimento parcial da falha (seta).

Ficou evidente, nas radiografias seriadas e na tomografia, que o implante foi coberto por uma ponte óssea, contínua com o osso receptor proximal e distal, apoiando-se sobre e entre o enxerto, o que reafirma o conceito de que o material osteocondutor serve de suporte para o crescimento ósseo (WOSNEY, 1994, CORNELL \& LANE, 1998).

Na necropsia, foi observado que, nos rádios que mostraram evidência radiológica de formação óssea (GI), na sexta semana, havia a formação de uma 
ponte completa, dura e de coloração rósea, com aspecto de osso vascularizado e em continuidade com o osso receptor. Nas primeiras seis semanas, o volume do calo foi exuberante, mas apresentou tendência à remodelação na nona semana. Esta intensa e precoce formação óssea foi devido aos fatores osteoindutores presentes na matriz, os quais, segundo LIND (1998), também foram responsáveis pela vascularização desse novo osso formado. No mesmo grupo, a tendência à remodelação observada na nona semana de pósoperatório, também mostrou a velocidade de maturação do osso novo, em comparação com os animais do grupo controle, no mesmo período, cujo tecido que preenchia parcialmente a falha tinha aparência de tecido fibroso, e somente nas extremidades foi semelhante a tecido ósseo.

Durante o período de observação microscópica, a matriz implantada foi ganhando celularidade, vascularização e população de células medulares, determinando que a reparação foi progressiva e isenta de infiltração de células inflamatórias e de reação do tipo corpo estranho. Além disso, segundo WOZNEY (1994) a biocompatibilidade da matriz foi um fator que permitiu o crescimento celular e proveu o ambiente condutor.

Segundo HOSNY \& SHARAWY (1985), nos enxertos de osso mineralizado, o conteúdo mineral residual deve ser reabsorvido antes que a matriz colágena e a BMP possam estimular a indução e antes que se efetue a completa substituição por osso novo pelos tecidos receptores. No entanto, no presente trabalho, a reabsorção da matriz desmineralizada foi mais rápida por causa da remoção dos minerais efetuada in vitro, que conforme VAIL et al. (1994), expõe a BMP, que é insolúvel em ácido.

$\mathrm{Na}$ terceira semana após a implantação, a matriz apresentava vasos sanguíneos e células mesenquimais invadiam os espaços, os antigos canais vasculares e o canal medular (Figura 2, A); outros canais foram abertos pela penetração de células gigantes multinucleadas semelhantes a osteoclastos, que estavam aderidas à matriz (Figura 2, B). A integração da matriz ao tecido receptor foi visível, devido à penetração de vasos sanguíneos. Foi possível a penetração de corações condróides no interior da matriz (Figura 3, A) e a formação de cartilagem aderida à sua periferia e partindo do periósteo ulnar.

Provavelmente, o colágeno foi sendo degradado lentamente pela colagenase, devido ao aspecto assumido pela matriz na terceira semana, que iniciava o processo de reabsorção juntamente com as células gigantes nucleadas que se localizavam perifericamente, sendo este simultaneamente substituído por matriz nova depositada pelos osteoblastos.

Na sexta semana, foi possível identificar que a ossificação ocorreu diretamente das células mesenquimais (intramembranosa), principalmente na periferia do enxerto, e de modelo cartilaginoso (endocondral), sendo a última característica mais evidente no interior da matriz. Havia grandes espaços vasculares com osteoblastos dispostos em linha, como se estivessem iniciando a formação aposicional (Figura 3, B). Foi possível observar que o processo de deposição óssea antecedia a reabsorção total da matriz implantada, semelhante às observações de HOSNY \& SHARAWY (1985) e ZHANG et al. (1997).

Na nona semana, o osso formado preenchia quase todo o espaço inicialmente ocupado pela matriz enxertada, que estava repleta de células e vasos. As células se arranjavam na forma de lamelas ao redor de espaços vasculares e ao longo das superfícies endosteal e periosteal. Os ósteons imaturos mostravam um eixo central grande e irregular (Figura 3, C). Havia

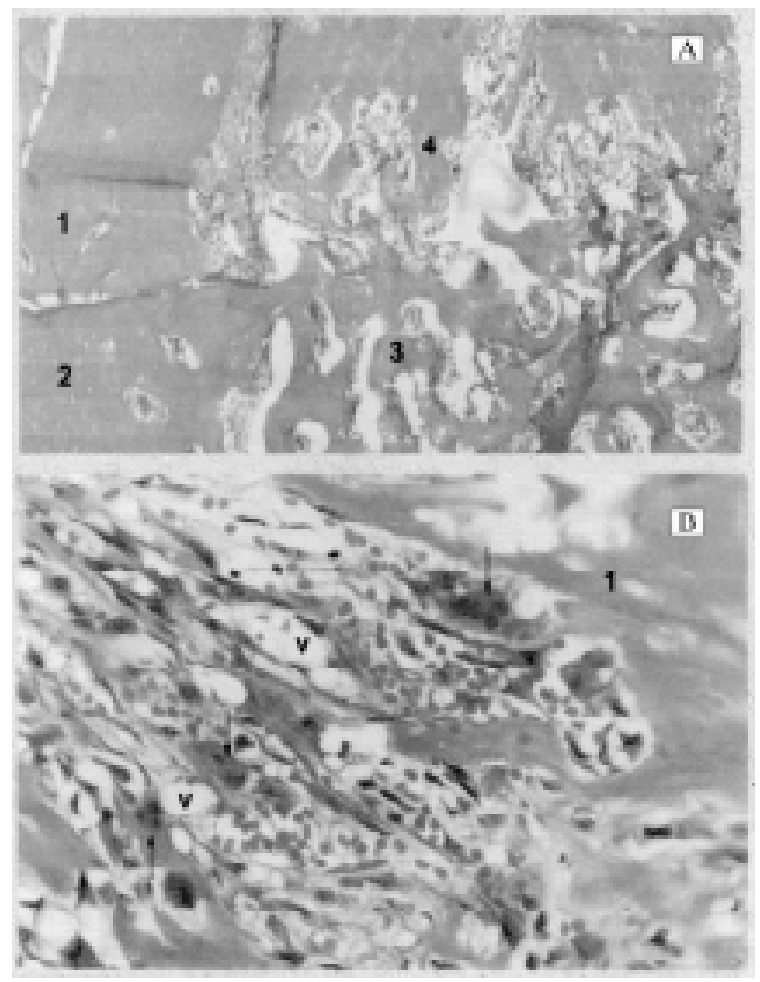

Figura 2 - Aspecto microscópico da MOD, na terceira semana de pós-operatório. Em A, corte longitudinal da região de osteointegração: enxerto (1); extremidade da falha (2); novo osso formado dentro do canal medular do osso receptor (3); invasão do enxerto por células que partem da medula e endósteo do osso receptor (4). H\&E. 100X. Em, B, corte longitudinal da região de osteointegração: matriz em reabsorção (1), vasos sanguíneos penetrando a matriz (v); células gigantes multinucleadas (setas). H\&E. 400X. 


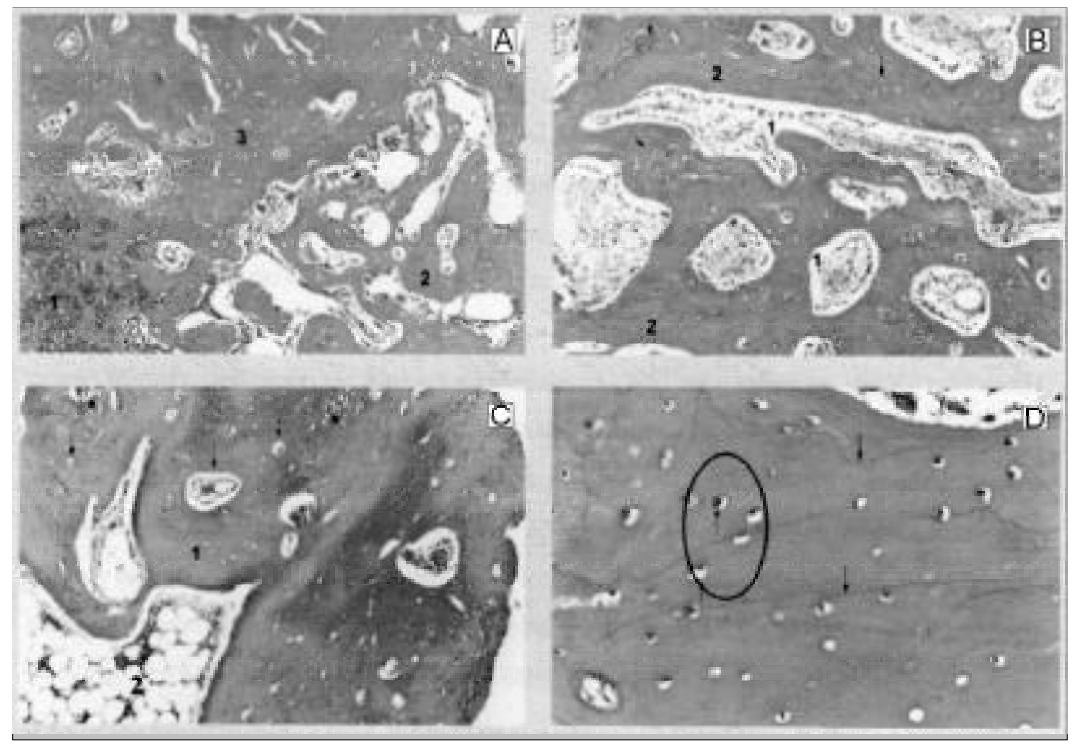

Figura 3 - Aspecto microscópico da evolução do processo de reparação óssea na região de implantação na MOD, em cortes transversais. Na terceira semana de pós-peratório (A): ossificação endocondral caracterizada por corações condróides (1); osso trabecular imaturo (2); restos de MOD (3). Na sexta semana (B): espaços vasculares amplos preenchidos por células blásticas (1); osso imaturo (2); corações condróides (setas). Na nona semana (C): início da formação de ósteons com canais vasculares amplos (setas); novo osso formado (1); canal medular preenchido por tecido hematopoiético (2). H\&E. 100X. Na $12^{\text {a }}$ semana (D): osso

também, ósteons secundários, osso trabecular e ossificação endocondral, não sendo evidenciada a MOD.

Na décima segunda semana, havia osso trabecular maduro formado, com lamelas arranjadas paralelamente à superfície periosteal, ósteons típicos, com canal de Havers central envolvido por anéis concêntricos de células. Havia também canais vasculares no osso cortical, e a cavidade medular era celular. Linhas de cimentação foram visíveis, denotando continuidade do processo de remodelação, pela deposição de novos ósteons, caracterizando um processo de maturação do osso (Figura 3, D). As características histológicas da região da falha que apresentou preenchimento parcial no coelho do GII (controle) foram de formação óssea com trabéculas dispostas em forma desorganizada e ausência de cortical e canal medular.

Os dados histológicos da evolução do processo de reparo caracterizaram os dois tipos de ossificação, com tecido ósseo depositado a partir da diferenciação das células tronco em células osteogênicas e de modelo cartilaginoso. Segundo NIDOLI et al. (1999), a predominância de ossificação intramembranosa na periferia do enxerto pode ser explicada pela maior tensão de oxigênio neste local, devido ao contato da MOD com vasos sanguíneos dos tecidos adjacentes. Já a ossificação endocondral, predominava no interior do implante, no qual havia poucos capilares e, conseqüentemente, menor tensão de oxigênio.

No estudo da fluorescência da tetraciclina, na terceira semana, áreas de fluorescência irregulares e amorfas foram observadas no osso trabecular recém-depositado. $\mathrm{Na}$ sexta semana, foi possível identificar a formação de osso lamelar, como linhas de eixos regulares, com anéis de fluorescência. Nos ósteons, o anel de fluorescência mais externo correspondia aos três primeiros dias de aplicação da tetraciclina, e o anel mais interno, aos três últimos dias de aplicação, enquanto a banda de fluorescência intermediária correspondia aos sete dias de intervalo entre as aplicações de antibiótico. Na nona e décima segunda semanas, estes anéis de fluorescência foram predominantes, evidenciando a maturidade óssea e o aspecto progressivo da reparação.

\section{CONCLUSÕES}

Com base nos resultados, pode-se concluir que a matriz óssea desmineralizada em ácido clorídrico $0,6 \mathrm{~N}$ e preservada em etanol $70 \%$ acelera o processo de formação óssea, devido a fatores indutores inerentes à matriz, e que os canais vasculares, as lacunas e o canal medular da matriz óssea homóloga desmineralizada servem de arcabouço para a penetração celular, determinando osteocondução. Portanto, a matriz óssea homóloga desmineralizada pode ser considerada material alternativo ao enxerto ósseo autólogo fresco, no preenchimento de falhas osteoperiosteais.

\section{FONTES DE AQUISIÇÃO}

a. Acepran $1 \%$, Univet. São Paulo, SP.

b. Zoletil 50, Virbac. São Paulo, SP.

c. Penicilina G benzatina, Eurofarma. São Paulo, SP.

d. Regular double cutting (22,2 mm X 0,6 mm), Dentorium. New York, NY.

e. Terramicina injetável, Pfizer. Rio de Janeiro, RJ.

f. Nikon Eclipse E600. Tókio, Japan. 


\section{REFERÊNCIASBIBLIOGRÁFICAS}

BROWN, D.M. et al. Osteochondral allografts with an intramedullary muscle flap in rabbits. Clin Orthop, n.334, p.282-290, 1997

CORNELL, C.N.; LANE, J.M. Current understanding of osteoconduction in bone regeneration. Clin Orthop, n. 355 p.267-273, 1998

HOSNY, M.; SHARAWY, M. Osteoinduction in rhesus monkeys using demineralized bone powder allografts. J Oral Maxill Surg, v.43, p.925-931, 1985.

LIND, M. Growth factor stimulation of bone healing: effects on osteoblasts, osteotomies and implants fixation. Acta Orthop Scand, Supplementum, v.69, n.283, p.1-37, 1998.

MORONE, M.A., BODEN, S.D. Experimental posterolateral lumbar spinal fusion with a demineralized bone matrix gel. Spine, v.23, n.2, p.159-167, 1998.

NADE, S.; BURWELL, R.G. Decalcified bone as a substrate for osteogenesis: an appraisal of the interrelation of bone and marrow in combined grafts. J Bone Joint Surg, v.59-B, n.2, p. $189-196,1977$

NIDOLI, M.C.; NIELSEN, F.F.; MELSEN, B. Endochondral vs. intramembranous demineralized bone matrices as implants for osseous defects. J Craniofacial Surg, v.10, n.3, p.177185,1999

SCHWARTZ, Z. et al. Ability of commercial demineralized freeze-dried bone allograft to induce new bone formation is dependent on donor age but not gender. J Periodont, v.69, n. 4, p.470-478, 1998

TULI, S.M.; SINGH, A.D. The osteoinductive property of decalcified bone matrix. J Bone Joint Surg, v.60-B, n.1, p.116-123, 1978

URIST, M.R.; McLEAN, F.C. Recent advances in physiology of bone. J Bone Joint Surg, v.45A, n.6, p.1305-1313, 1963.

VAIL, T.B.; TROTTER, G.W.; POWERS, B.E. Equine demineralized bone matrix: relationship between particle size and osteoinduction. Vet Surg, n.23, p.386-395, 1994.

VOLPON, J.B. A marcação do osso com substâncias fluorescentes. Rev Bras Ortop, v.20, n.5, p.207-210, 1985.

WOZNEY, J.M. Molecular biology of the bone morphogenetic proteins. In: URIST, M.R., OCONNOR, B.T., BURWELL, R.G. (Eds). Bone grafts, derivates and substitutes. Oxford: Butterworth Heinemann, 1994. p.397-413.

ZHANG, M.; POWERS, R.M.; WOLFINBARGER, L. Effects on the demineralization process on the osteoinductivity of demineralized bone matrix. J Periodont, v.68, n.11, p.10851092, 1997. 